\title{
Brief report: The relationship between writing transcription skills and writing measures differs between children who self-report being monolingual or bilingual.
}

\author{
Emily Talbot, Gareth J. Williams, and Rebecca F. Larkin
}

Division of Psychology, Nottingham Trent University, Nottingham, United Kingdom

Correspondence concerning this article should be sent to Gareth J. Williams, Division of Psychology, Nottingham Trent University, Burton Street, Nottingham, United Kingdom. NG1 4BU. E-mail: gareth.williams@ntu.ac.uk, Tel: +44 (0)115 8484125

Emily Talbot is a masters student at Nottingham Trent University, Gareth Williams is a senior lecturer at Nottingham Trent University, Rebecca Larkin is a senior lecturer at Nottingham Trent University. 


\title{
Brief report: The relationship between writing transcription skills and writing measures differs between children who self-report being monolingual or bilingual.
}

\author{
This study explored how the skills involved in writing were associated with \\ written language measures in children who self-reported being bilingual or \\ monolingual. Twenty children were matched for age and gender and took part in \\ a writing task and a series of tasks to measure writing transcription skills. The \\ results found that there was no difference in the writing measures for either \\ group. There was a different pattern of significant associations between the \\ transcription skills and the writing measures for the two groups. The results are \\ discussed in terms of the different ways in which a complex task like writing can \\ be accomplished successfully.
}

Keywords: bilingualism; writing; spelling; self-report

\section{Introduction}

Writing is an important skill in the primary school curriculum in the UK (Department for Education, 2011; Williams \& Larkin, 2012). However, how a child's language abilities contribute to their writing and whether these contributions differ for monolingual children and bilingual children is an overlooked field of research and one that this study contributes towards. The specific focus in this study is on the transcribing skills of spelling, orthographic awareness, and writing speed.

Transcribing, or transcription, skills are often one of four processes that are thought to make up writing skills. For example Berninger \& Winn (2006) argued that transcription interacts with the processes that keep a writer working towards the goal of the written piece (executive functions), that generate language, and with a flexible memory store where information can be accessed from either of the three processes. Although frameworks like this show how complex writing is, it is not clear whether 
these processes interact in the same way for bilingual writers. Bilingual and monolingual adults, for example, perform differently on various language and executive control tasks (Bialystok, Craik, \& Luk, 2008).

The present study asked children to self-report their competencies in English and a second language. The resultant groups were compared on a writing task that provided measures of writing quality and writing quantity. In addition, several transcription measures were taken so that it was possible to assess the role of transcription skills in monolingual and bilingual children.

The aims of the study were (1) to see if there were differences between bilingual and monolingual children on several quantity and quality writing measures, (2) whether the patterns of association between transcription skills and the writing measures were similar for monolingual and bilingual children.

\section{Method}

\section{Participants}

From a larger sample of 90 children, 21 children fulfilled the criteria of being bilingual. For this, the child would need a score of four on the monolingual part of the language self-assessment and a score of three or four on the bilingual part of the assessment. It was possible to match, by age and gender, 20 bilingual children (nine females) to selfreported monolingual children. These children had a score of four on the monolingual part of the language assessment but a score of two or less on the bilingual part. All the children were from the same school in the Midlands of the United Kingdom, the school is in an area that has a moderate socio-economic status and less than one in ten children had a statement of special education needs; below the typical level for a school in the UK. 


\section{Language Measures}

\section{Self-assessment of language.}

There was a monolingual (English) and a bilingual section for the self-assessment and each comprised of the same four questions: "Can you understand spoken instructions?", "Can you read a storybook?", "Can you spell the days of the week?", and "Can you count out loud to twenty?". In the bilingual section, children were first asked to nominate their other language. All children reported "yes" to all four questions in the monolingual section of the questionnaire. For the bilingual section, the modal monolingual response was "yes" to one question, and for the bilingual children the responses were split between "yes" for three questions $(n=10)$ and "yes" for four questions $(n=10)$. This resulted in a significant chi square $\left(d f=4, \chi^{2}=40, \mathrm{p}<.01\right)$. There were a range of languages indicated by the self-reported bilingual children 13 reported Spanish, one child each reported French, Greek, Gujarati, and Mandarin, one child reported three languages (Italian, Spanish, and French) and one child reported "various".

\section{Ability measures}

Orthographic awareness task.

Orthographic awareness task (Cunningham, Perry, Stanovich \& Share. 2002). Children decided between two words for each of the 23 items. One was the correct spelling, the other was an orthographically similar nonword. Each correct choice was awarded one point. Items 22 and 23 were removed to increase the reliability alpha from .61 to .71 .

\section{Spelling task}

The 20 words were taken from the Children's Printed Word Database website in order that they were suitable for the age group. The list was read aloud to the class. First the 
word on its own, then in a sentence context, and finally on its own again. Each correctly spelt word was awarded one point.

Writing speed task

Children copied lowercase letters of the alphabet, that were printed on the response sheet, for two minutes. The score was the number of correctly copied letters.

Writing task

The storyboard consisted of a set of pictures showing a boy and girl visiting the beach and eating ice creams and was based on the same materials as Williams and Larkin (2012). Children were given two minutes to look and think about the pictures and ten minutes to write a story based on the pictures. The measures were word count, lexical diversity (number of types of words), the proportion of spelling errors, and a measure of the quality of the writing based on the Wechsler Objective Language Dimensions classification (Rust, 1996).

\section{Procedure}

The tasks were completed in a class-wide environment and instructions were given before each task was completed.

\section{Results}

The comparisons between monolingual and bilingual self-report groups on the ability measures showed no significant differences $(p>.05)$ for spelling ability, writing speed, or orthographic awareness (See Table 1 for descriptive statistics). In terms of writing measures, there was no significant difference between the two groups in any measure: overall writing quality, proportion of spelling errors, word count, or lexical diversity.

\section{Table 1 Here}

Even though the two groups were equally able at writing, it was possible that the way in which the ability scores, and age, associated with the writing measures differed 
for both groups. Separate zero-order correlations for each group were carried out. There were four main differences in the patterns of correlations between the monolingual and bilingual groups. For brevity, only the significant $(p<.05)$ correlations are reported in full. Although spelling ability and the proportion of spelling errors (monolingual, $r=-$ .66; bilingual, $r=-.49$ ) and spelling ability and the writing quality (monolingual, $r=$ .56; bilingual, $r=.58$ ) was significantly correlated in both groups, the monolingual children had further significant associations between spelling ability and word count $(r$ $=.53)$ and spelling ability and lexical diversity $(r=.66)$ whereas these associations were not significant for the bilingual group. Writing speed was significantly associated with word count in the bilingual group $(r=.54)$ but not the monolingual group. Orthographic awareness was significantly associated with lexical richness in the monolingual group $(r$ $=.56)$ but not the bilingual group. These patterns remained when age was taken into account. Finally, age was significantly associated with the quality of writing in the monolingual group $(r=.51)$ but not the bilingual group.

\section{Discussion}

We asked children to self-report their level of bilingualism and compared the two groups, self-reported monolingual children and bilingual children, on a range of writing measures. Primarily we were interested in whether the associations between the two groups were the same. One of the main findings was that, in monolingual children, spelling was associated with word count and lexical diversity but there were no equivalent associations in the bilingual group. Both lexical diversity and word count measure the quantity of text as opposed the quality of text, quality was a measure where both groups showed significant associations with spelling ability. This finding suggests that some aspect of bilingualism is helping these writers that, in monolingual children, is supported by spelling ability. One possibility is the way in which lexical access 
differs between monolingual and bilingual children. Bilingual children are likely to have two linguistic reference points, from at least two languages, for the same information and this might change the way in which linguistic processing contributes to writing quantity. However, this does not provide bilingual children with the capacity to write more, as both groups wrote a similar amount of words and had similar lexical diversities.

There are two alternative interpretations of the findings. The first is that the findings are a function of the ceiling effect found in both the spelling ability task and the orthographic awareness task. This might have limited the variance in both tasks and subsequently the correlational analysis results. The second is that the findings are because of the nature of self-reports. It is possible that self-reporting, in this study, measured confidence instead of ability. Many of the bilingual children reported "Spanish" as their second language and this might have been the confidence drawn from Spanish lessons at the school.

Overall the study highlights that, although different groups of children might be equivalently capable in their writing, there are different pathways to achievement in complex tasks, like writing, that integrate a range of different processes (Berninger \& Winn, 2006). From an educational context, this reinforces the need to see the child as an individual in their learning journey.

\section{References}

Berninger, V. W., \& Winn, W. (2006). Implications of advancements in brain research technology for writing development, writing instruction, and educational evolution. In 
S. G. MacArthur, \& J. Fitzgerald (Eds.), Handbook of writing research (pp. 96-114). New York: Guilford Press.

Bialystock, E., Craik. F., \& Luk, G. (2008). Cognitive control and lexical access in younger and older bilinguals. Journal of Experimental Psychology. Learning Memory and Cognition. 34(4), 859-873.

Cunningham, A. E., Perry, K. E., Stanovich, K. E., \& Share, D. L. (2002). Orthographic learning during reading: Examining the role of self-teaching. Journal of Experimental Child Psychology, 82(3), 185-199. doi:10.1016/S0022-0965(02)00008-5

Department for Education Key Stage 2: English En3 writing. (2011). Retrieved February 6, 2012, from http://www.education.gov.uk/schools/teachingandlearning/curriculum/primary/b001988 74/english/ks2/en3

Rust, J. (1996). The manual of the Wechsler objective language dimensions (WOLD): UK edition. London: The Psychological Corporation.

Williams, G. J., \& Larkin, R. F. (2012). Narrative writing, reading and cognitive processes in middle childhood: What are the links? Learning and Individual Differences, 28, 142-150. doi:10.1016/j.lindif.2012.08.003 
Table 1. Descriptive statistics comparing self-reported monolingual and bilingual children on the ability measures

Monolingual Bilingual

$$
(\mathrm{N}=20) \quad(\mathrm{N}=20)
$$

\begin{tabular}{lccccc} 
Measures & Mean & SD & Mean & SD & $\alpha$ \\
\hline Age (months) & 99.45 & 6.21 & 99.85 & 6.2 & - \\
Spelling ability & 16.6 & 3.27 & 17.25 & 3.49 & .84 \\
Writing speed & 73.85 & 24.31 & 86.15 & 26.33 & - \\
Orthographic awareness & 20.5 & 1.28 & 20.8 & 0.7 & .71 \\
Writing quality & 11.55 & 3.61 & 14.05 & 4.32 & .93 \\
Proportion of spelling errors & 0.11 & 0.08 & 0.11 & 0.13 & - \\
Word count & 75.75 & 22.26 & 71.25 & 23.1 & - \\
Lexical diversity & 45.55 & 11.61 & 44.90 & 11.32 & -
\end{tabular}

